\title{
Article \\ Outdoor Test Cell Modelling with Modelica
}

\author{
Thomas Wüest ${ }^{1, *(\mathbb{D})}$, Philipp Schuetz ${ }^{2}$ and Andreas Luible ${ }^{1}$ \\ 1 Competence Centre Building Envelope, Institute of Civil Engineering, Lucerne University of Applied \\ Sciences and Arts, Technikumstrasse 21, CH-6048 Horw, Switzerland; andreas.luible@hslu.ch \\ 2 Competence Centre Thermal Energy Storage, Institute for Mechanical Engineering and Energy Technology, \\ Institute for Natural Sciences and Humanities, Lucerne University of Applied Sciences and Arts, \\ Technikumstrasse 21, CH-6048 Horw, Switzerland; philipp.schuetz@hslu.ch \\ * Correspondence: thomas.wueest@hslu.ch; Tel.: +41-41-349-3842
}

Received: 26 August 2019; Accepted: 23 September 2019; Published: 25 September 2019

\begin{abstract}
The experimental setup implements a simplified PASSYS test cell construction, which is combined with a detailed simulation to reduce measurement effort. To analyze the cell's dynamic behavior, the test cell was closely monitored with thermal sensors, and different static and dynamic heating modes were applied during a three-week calibration period. Co-heating tests were performed for steady-state measurements and cyclic heating periods account for the transient behavior of the test cell. The cells response was compared to the results of transient simulations with the software packet Modelica. The equation based Modelica framework allowed a detailed transient thermal simulation of the test cell's dynamic to be set up that shows close agreement with the measurements. In addition, the flexibility of Modelica allowed unforeseen events affecting the experimental setup to be replicated, thereby ensuring an uninterrupted heat flow history of all surfaces. More than $96 \%$ of the predicted air temperatures ( $1 \mathrm{~min}$ resolution) match the experimental values within an error band of $\pm 1.5 \mathrm{~K}$, and $90 \%$ of all predictions are within $\pm 1.0 \mathrm{~K}$.
\end{abstract}

Keywords: outdoor test cell; building dynamic simulations; experimental validation; real-world test system; monitoring data; Modelica

\section{Introduction}

The emergence of new façade designs over the past decades has driven the development of methods for performance characterization and tests of compliance with design targets. Compliance tests often follow standards relying on performance metrics from measurement under steady-state conditions or governed by specific test schedules. While such tests can be reliably performed in the controlled environment of laboratories, they cannot explain the performance of a façade under real-world, outdoor conditions. Especially dynamic, responsive or adaptive façade elements necessitate real-world testing conditions, since their response dynamic loads cannot be replicated in a static testing environment [1]. To characterize the behavior of building components under realistic outdoor conditions, simulation model as well as methods and facilities for outdoor measurement were developed.

Domain-specific building performance simulation software allows the dynamic behavior of the building and its components to be studied over extended evaluation periods. The built-in models for common system components and simulation processes however limits their flexibility in the in-depth analysis of custom components. Multi-domain modeling environments, on the other hand, provide less predefined components for particular applications, but offer a tool to model the behavior of the system on external variables [2,3]. Modelica is such an object orientated, equation based multi-domain simulation environment, that enables the detailed thermal modeling of building components $[4,5]$. It provides an in-depth view of the system's components. All components can be edited, combined or extended. The software is equipped with standard thermal components and can utilize third-party 
component libraries such as AixLib [6] or Buildings Library [7,8]. AixLib and Buildings Library are free open-source libraries with dynamic simulation models for thermal systems, HVAC systems, HVAC control, room models and many more on a building or district level. Both support a flexible and fast modelling of new or existing buildings for analysis, improvement or parameter studies. Although the versatility of Modelica in system modelling offers great flexibility in the application to building modelling, thorough testing of the suitability and validity of models is of utmost importance.

To measure the performance of building components under realistic conditions, a test cell (TC) with controlled internal conditions is exposed to the outdoor environment. The PASSYS (passive solar components and systems testing)/PASSLINK test cells and procedures [9] are among the most widely known outdoor tests as of today. The PASSYS Project started in the 1980s [10] and defined the layout and equipment of a TC with the aim to provide a harmonized and accurate approach to performance measurements on building components. The PASSYS TCs comprise of a highly insulated test room with a removable southern wall and an adjoining service room in the northern part. Initially, the test procedures relied on steady-state evaluations. The stationary condition changed with a revision of the test and analysis methods, now referred to as PASSLINK TCs [11], that implement a test environment under transient conditions. Nevertheless, various other TCs for many different objectives have been built. Depending on research purposes, smaller test boxes [12] or real scale facilities [13-15], to name a few, were used.

PASSYS and PASSLINK are elaborate TC designs that combine a range of different sensors to monitor heat transfer processes [16]. A simplified design is proposed that combines readings from an extensive network of temperature sensors with a validated model to simulate those phenomena that are not directly monitored and thereby reduce the heterogeneity of measurement equipment. In particular, the direct measurement of heat flux through building elements is replaced by computational methods based on detailed monitoring of the temperature profiles within the constructions.

This research presents such a simplified, experimental TC that was set up to support the development of the Solar Energy Balanced Façade (SEBF) $[17,18]$, a novel façade design with a controlled, integrated thermal storage. To accelerate the development of the SEBF as well as the TC, a model was implemented to study the heat flux through the façade. However, this model has been verified only by small-scale experiments. The TC is intended to (a) be a stable conditioned room (CR) to investigate the environmental reaction of the test façade and (b) take measurements of the TC itself to compare it to the new modeling approach. Point (a) belongs to the future use of the TC; it is not content of this article. For (b), the TC is monitored while different heat sources and heat modes were applied in the $\mathrm{CR}$ to measure the TC's response. Because the modeling approach supports transient simulations, the test method should also be adapted to test the dynamic behavior instead of a quasi-stationary characterization. The simulation of the TC relies on the same basics as the theoretical analysis of the SEBF $[17,18]$. Therefore, first simulation errors could be detected before the real prototypes could be measured.

To enable an encompassing validation of the model, it is necessary to isolate modelling error from discrepancies caused by different interior and exterior conditions in simulation and measurement. Therefore, in the presented work, the comparison of model and outdoor measurement is focused on the TC, prior to the introduction of the SEBF. The development of the TC and the presented validation of its digital counter-part shall thus:

- provide a realistic test-bed for future validations of façade models,

- thereby prepare the validation of a model of the SEBF and

- foster the cost-effective design and operation of thermal TCs.

This contribution is structured as follows. Section 2 describes the TC design and monitoring equipment. Section 3 documents the initial calibration measurement of the TC without transparent façade constructions, and Section 4 describes the modeling approach. The results of the continuous 
measurement over a period of 21 days and the comparison with the simulation results are given in Section 5. Eventually, in Section 6, the results are discussed and a conclusion is drawn.

The data collected through measurements and simulations that were used to prepare the figures and tables in this work are provided as supplementary material with this article. This allows other researchers to compare their models or TCs to this work.

\section{Design and Construction of the Test Cell}

\subsection{Location}

The TC complements existing testing facilities for façade on the campus of Lucerne University of Applied Sciences and Arts in Horw, Switzerland [19]. The perfectly south-oriented cell is raised to a level of $3.0 \mathrm{~m}$ above ground to minimize obstruction of the southern wall with its aperture (see Figure 1).

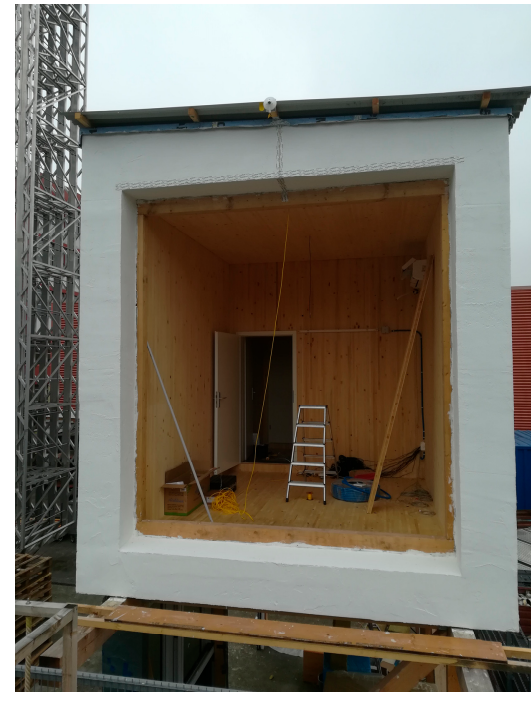

(a)

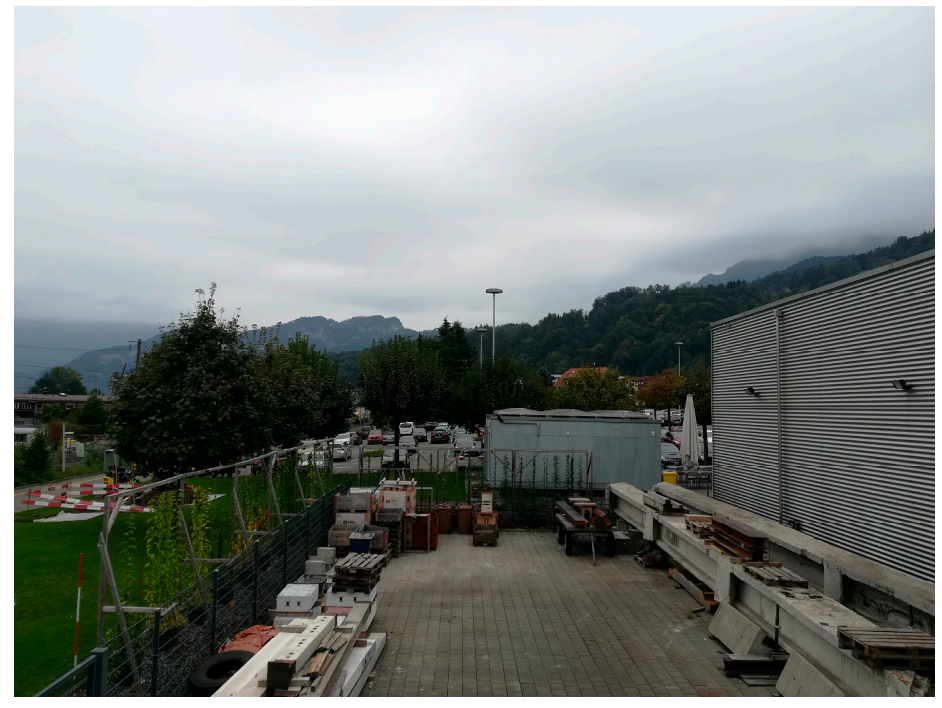

(b)

Figure 1. (a) Front view of the test cell opening (under construction) and (b) outlook.

The southern wall is supposed to be a flexible opening to host and characterize façade prototypes. For the analysis in this paper, the southern wall was insulated in the same manner as the walls to gain information about the TC's thermal behavior.

\subsection{Design of the Test Cell}

The experimental design is inspired by the PASSYS TC $[9,20]$. It is built as a highly insulated wooden enclosure containing two rooms (see Figure $2 \mathrm{a}, \mathrm{c}$ ). The CR has an area of $8.6 \mathrm{~m}^{2}$ and volume of $27.6 \mathrm{~m}^{3}$ and features an aperture of $2.80 \mathrm{~m} \times 2.98 \mathrm{~m}$ in its southern wall that can be equipped with a test façade specimen. The CR is connected to a maintenance room (MR) of $6.0 \mathrm{~m}^{2}$ area and $19.3 \mathrm{~m}^{3}$ volume in the north direction. The entrance at the north façade of the MR, as well as the passage between the two rooms, consist of two independent, insulated doors to reduce thermal bridges and air infiltration.

The enclosure is designed to minimize intersections that could form heat bridges. A horizontal platform, mounted on a scaffold to raise the TC to the desired level, forms the base of the cell. The load bearing structure of the TC is based on $40 \mathrm{~mm}$ wooden plates, which are assembled in a way to minimize thermal bridges and carry all structural loads (see Figure 2c).

The longitudinal walls as well as the wall insulation are standing on the platform. Wooden beams of $200 \times 40 \mathrm{~mm}$ are installed between the longitudinal walls and reinforce the inner floor plate at intervals of $1.0 \mathrm{~m}$. The cavity below and between the beams is completely insulated. The ceiling plate 
and the partition wall between the two rooms are mounted between the walls. The rafter beams of the roof intersect the longitudinal walls by $100 \mathrm{~mm}$ and support longitudinal beams of $50 \mathrm{~mm} \times 50 \mathrm{~mm}$ that hold a corrugated sheet forming the ventilated roof.

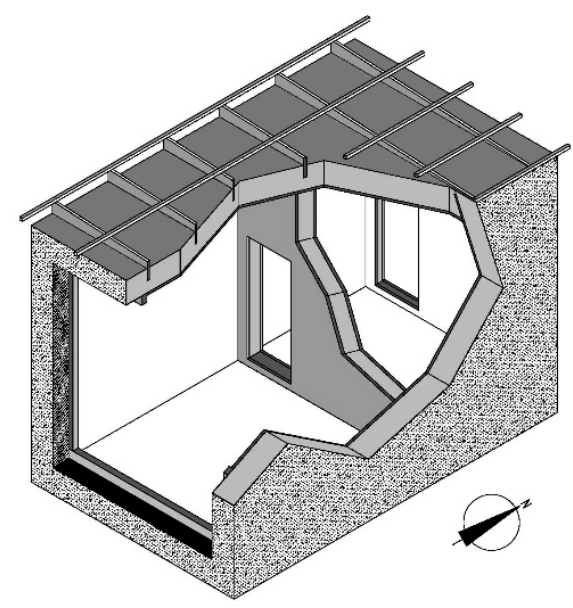

(a)

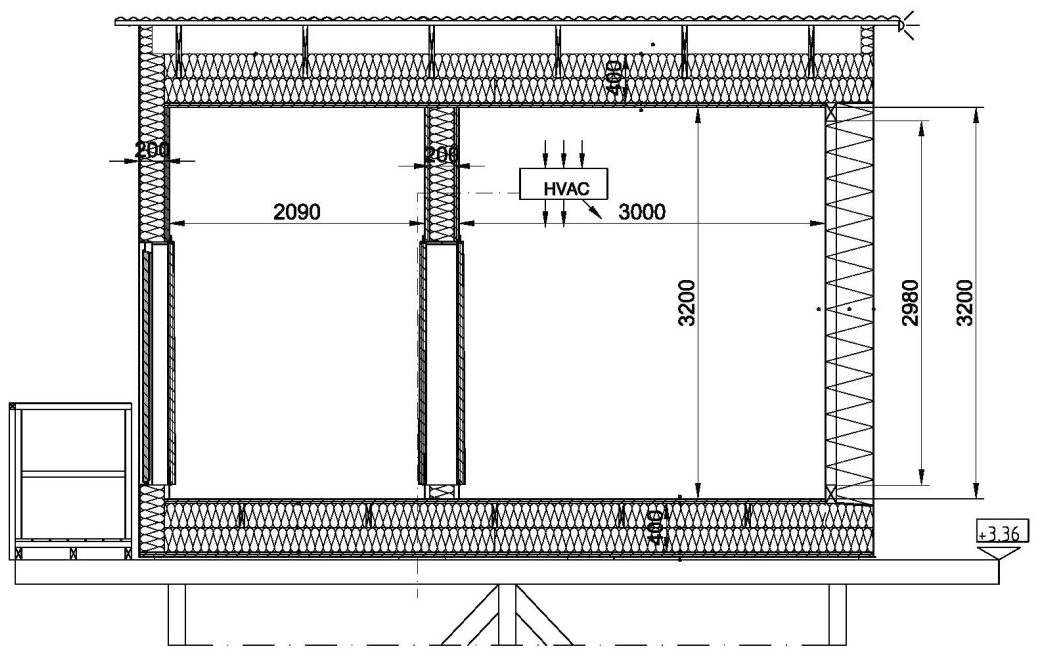

(c)

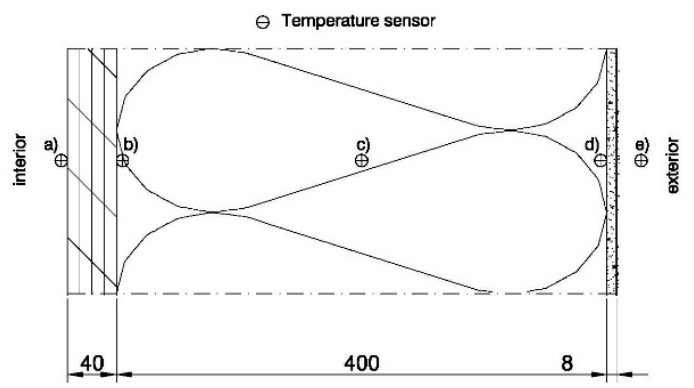

(b)

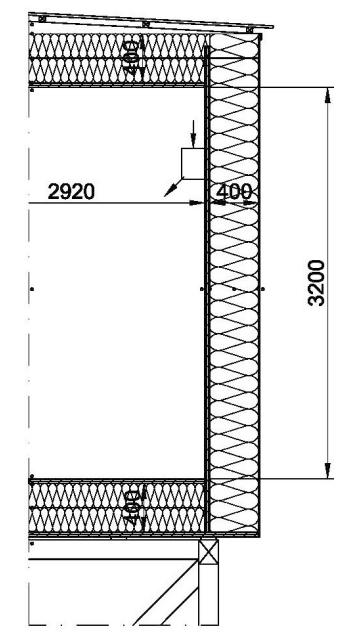

Figure 2. Geometry of the test cell (TC) with (a) isometric view, (b) sensor positioning detail for wall (other surfaces in the same manner) and (c) longitudinal (left) and cross section (right) of the TC.

Floor, ceiling and longitudinal walls are insulated with rock wool panels of $400 \mathrm{~mm}$ thickness (Flumroc CompactPro) ( $\mathrm{U}=0.08 \mathrm{Wm}^{-2} \mathrm{~K}^{-1}$ according to the simplified procedure for homogenous layer in EN 6946 [21], for details see Table 1). The exterior wall toward the north direction and the inner partition wall are insulated by panels of $200 \mathrm{~mm}$ thickness of the same material. The doors are double-sided to reduce heat flux. This means that each passage opening is equipped with two doors, which are comprised of a door, an air gap and second door. To minimize thermal bridges, the external wall insulation consists of one layer of insulation (a $400 \mathrm{~mm}$ thick layer of rock wool for the longitudinal and south-facing wall and a $200 \mathrm{~mm}$ thick panel for the wall in north direction) that is only glued on the wooden plates without the use of intersecting screws. Floor and ceiling insulation consist of two layers of $200 \mathrm{~mm}$ thick panels of rock wool. The panels are overlapping so that no continuous joints pass the entire height of the insulation. All external surfaces are plastered and painted with white color. 
Table 1. Material properties of building materials for the test cell.

\begin{tabular}{|c|c|c|c|c|}
\hline Construction & $\begin{array}{l}\text { Conductivity } \\
\lambda\left[\mathrm{Wm}^{-2} \mathrm{~K}^{-1}\right]\end{array}$ & $\begin{array}{c}\text { Density } \\
\rho\left[\mathrm{kgm}^{-3}\right]\end{array}$ & $\begin{array}{c}\text { Heat Capacity } \\
\text { c }\left[\mathrm{Jkg}^{-1} \mathrm{~K}^{-1}\right]\end{array}$ & $\begin{array}{c}\text { Thickness } \\
t \text { [mm] }\end{array}$ \\
\hline $\begin{array}{l}\text { Ceiling } \mathbf{U}=\mathbf{0 . 0 8 1} \mathbf{~ W m}^{-\mathbf{2}} \mathbf{K}^{\mathbf{- 1}} \\
\text { Internal SHTC } \\
\text { Wooden plate (Schuler) } \\
\text { Insulation (Flumroc CompactPro) } \\
\text { Ventilated air gap } \\
\text { Corrugated sheet } \\
\text { External SHTC** }\end{array}$ & $\begin{array}{c}10 \\
0.10 \\
0.034\end{array}$ & $\begin{array}{c}430^{* *} \\
80\end{array}$ & $\begin{array}{c}1980^{* *} \\
870\end{array}$ & $\begin{array}{c}40 \\
400 \\
50 \text { to } 250\end{array}$ \\
\hline $\begin{array}{l}\text { Floor } \mathbf{U}=\mathbf{0 . 0 7 8} \mathbf{~ W m}^{-2} \mathbf{K}^{-1} \\
\text { Internal SHTC } \\
\text { Wooden plate (Schuler) } \\
\text { Insulation (Flumroc CompactPro) } \\
\text { Wood } \\
\text { External SHTC }\end{array}$ & $\begin{array}{c}5.9 \\
0.10 \\
0.034 \\
0.10 \\
25\end{array}$ & $\begin{array}{l}430^{* *} \\
80 \\
430^{* *}\end{array}$ & $\begin{array}{l}1980^{* *} \\
870 \\
1980^{* *}\end{array}$ & $\begin{array}{c}40 \\
400 \\
40\end{array}$ \\
\hline $\begin{array}{l}\text { Wall East/West } \mathbf{U}=\mathbf{0 . 0 8 1} \mathbf{W m}^{-\mathbf{2}} \mathbf{K}^{-\mathbf{1}} \\
\text { Internal SHTC } \\
\text { Wooden plate (Schuler) } \\
\text { Insulation (Flumroc CompactPro) } \\
\text { Plaster (Sto LevelNovo) } \\
\text { External SHTC }\end{array}$ & $\begin{array}{c}7.7 \\
0.10 \\
0.034 \\
0.3 \\
25\end{array}$ & $\begin{array}{c}430^{* *} \\
80 \\
1000\end{array}$ & $\begin{array}{c}1980^{* *} \\
870 \\
1000\end{array}$ & $\begin{array}{c}40 \\
400 \\
8\end{array}$ \\
\hline $\begin{array}{l}\text { Partition wall } \mathbf{U}=\mathbf{0 . 1 4 4} \mathbf{W m}^{-2 \mathrm{~K}-\mathbf{1}} \\
\text { Internal SHTC } \\
\text { Wooden plate (Schuler) } \\
\text { Insulation (Flumroc CompactPro) } \\
\text { Wooden plate (Schuler) } \\
\text { External SHTC }\end{array}$ & $\begin{array}{c}7.7 \\
0.10 \\
0.034 \\
0.10 \\
7.7\end{array}$ & $\begin{array}{l}430^{* *} \\
80 \\
430^{*}\end{array}$ & $\begin{array}{c}1980^{* *} \\
870 \\
1980^{*}\end{array}$ & $\begin{array}{c}40 \\
200 \\
40\end{array}$ \\
\hline $\begin{array}{l}\text { North Wall U = } \mathbf{0 . 1 5 4} \mathbf{W m}^{-2} \mathbf{K}^{-\mathbf{1}} \\
\text { Internal SHTC } \\
\text { Wooden plate (Schuler) } \\
\text { Insulation (Flumroc CompactPro) } \\
\text { Plaster (Sto LevelNovo) } \\
\text { External SHTC }\end{array}$ & $\begin{array}{c}7.7 \\
0.10 \\
0.034 \\
0.3 \\
25\end{array}$ & $\begin{array}{l}430^{* *} \\
80 \\
1000\end{array}$ & $\begin{array}{c}1980^{* *} \\
870 \\
1000\end{array}$ & $\begin{array}{c}40 \\
200 \\
8\end{array}$ \\
\hline $\begin{array}{l}\text { Doors } \\
\text { Door } \\
\text { Air gap (north/partition wall) } \\
\text { Door }\end{array}$ & $\begin{array}{l}0.23 \\
0.23\end{array}$ & $\begin{array}{l}250 \\
250\end{array}$ & $\begin{array}{l}1980 \\
1980\end{array}$ & $\begin{array}{c}40 \\
150 / 250 \\
40\end{array}$ \\
\hline
\end{tabular}

${ }^{*} \mathrm{~h}_{\text {int }} / \mathrm{h}_{\text {ext }}$ according EN ISO 6946 [21]. ** The manufacturer tabulates a range of $430-450 \mathrm{kgm}^{-3}$ for density and $1980-2400 \mathrm{~J} \mathrm{~kg}^{-1} \mathrm{~K}^{-1}$ for heat capacity.

\subsection{Heating, Ventilation, and Cooling Equipment}

To maintain a constant interior temperature, a split-system heating, ventilation, and air conditioning (HVAC) unit (Airklima AK8540 from Airklima, Hildesrieden, Switzerland) is installed on the east wall of the CR (heat-pump based air conditioning unit). The key features are given in Table 2. Besides the low-power monitoring equipment, no other internal gains are present during regular operation.

The HVAC unit is installed close to the upper north corner of the east wall in the CR (see Figure 2c). All piping is insulated and directly routed from the unit through the partition wall and downwards in the southeast corner of the MR and finally through the floor to the external part of the HVAC system. 
Table 2. Specification of the split air-conditioning unit of the TC.

\begin{tabular}{ccc}
\hline Airklima AK8540 & From & To \\
\hline Electrical consumption in cooling mode & $1.0 \mathrm{~kW}$ & $3.3 \mathrm{~kW}$ \\
Ambient temperature range for heating & $-15^{\circ} \mathrm{C}$ & $45^{\circ} \mathrm{C}$ \\
Electrical consumption in heating mode & $0.8 \mathrm{~kW}$ & $3.7 \mathrm{~kW}$ \\
Ambient temperature range for cooling & $-10^{\circ} \mathrm{C}$ & $25^{\circ} \mathrm{C}$ \\
Internal air volume flow & $260 \mathrm{~m}^{3} \mathrm{~h}^{-1 \text { band }}$ & $470 \mathrm{~m}^{3} \mathrm{~h}^{-1}$ \\
Range for temperature set point & $17^{\circ} \mathrm{C}$ & $30^{\circ} \mathrm{C}$ \\
\hline
\end{tabular}

\subsection{Monitoring Equipment}

For the monitoring of the TC, all its surfaces are equipped with one wire DS18B20 digital thermal sensors from Maxim Integrated, U.S.A. The specifications provided by the manufacturer are reported in Table 3.

Table 3. Specification of the DS18B20 digital temperature sensor employed for monitoring of the TC.

\begin{tabular}{ccc}
\hline DS18B20 & From & To \\
\hline Temperature & $-55{ }^{\circ} \mathrm{C}$ & $125{ }^{\circ} \mathrm{C}$ \\
Accuracy (within $-10{ }^{\circ} \mathrm{C}$ to $\left.85^{\circ} \mathrm{C}\right)$ & \multicolumn{2}{c}{ $\pm 0.5^{\circ} \mathrm{C}$} \\
Resolution & 9 bits & 12 bits (used) \\
Interface & Dallas Semiconductor 1-Wire \\
\hline
\end{tabular}

The manufacturer indicates for the temperature sensors DS18B20 only an accuracy of $\pm 0.5 \mathrm{~K}$. To gauge the temperature sensors mutually, a linear correction formula for the temperature readings of each sensor individually was determined as follows: all temperature sensors have been mounted in a water bath whose temperature is controlled by a thermostat Haake P5 with controller C10 from Huber. The temperature of the water bath was determined using temperature sensor $\mathrm{t} 110$ from Testo. To determine offsets and slopes of a linear correction formula for the temperature readings, the water bath was heated to temperatures of $20,30,40,50$, and $60^{\circ} \mathrm{C}$ (confirmed by readings of $21.9,30.2,40.3$, 50 , and $59.1{ }^{\circ} \mathrm{C}$ on the reference thermometer). At each temperature level, the sensors were read at least for $5 \mathrm{~min}$ as soon as the temperature readings did not change by more than $0.3^{\circ} \mathrm{C}$. The samples were recorded continuously, resulting in inter-measurement time intervals of $15-60 \mathrm{~s}$. Subsequently, for each sensor, the median of the temperature readings at each temperature level was calculated, and the median temperature values were fitted against the reference temperature values employing a least-squares fit (as implemented in the polyfit function from the SciPy package). The respective slope and intercept are then applied to correct the readings of the temperature sensor. The linear correction formula was applied to adjust the different offsets of the sensors (intercept) and to correct potentially different linearity (slope). This ensures a correct relative measurement of all sensors.

As each sensor increases the read-out time almost linearly, the 59 temperature sensors are distributed over seven raspberry pi microcontrollers collecting the individual measurement results balancing administration overhead and read-out times. For redundancy, all measurement values are stored on each raspberry computer locally, mirrored to the other raspberries via socket communication and submitted to a central installation of ThingsBoard via https socket communication.

The heat gain of the monitoring equipment was measured and considered with $4 \mathrm{~W}$ for each raspberry pi. Six of them are placed in the unconditioned MR and one in the CR.

As shown in Figure $2 b$, all walls of the $C R$, as well as the floor and ceiling, are equipped with five temperature sensors at the center, undisturbed area of each surface. These are positioned to measure:

(a) air temperature near surface,

(b) temperature at the outward surface of the wooden plate toward the insulation,

(c) insulation core temperature, 
(d) external surface of insulation, and

(e) external air temperature near wall.

In the MR, all walls, floor and ceiling are equipped with three thermal sensors each. Internal and external air temperature near the surface (a and e) are not measured.

In each room, one sensor is hanging from the ceiling to measure the air temperature in the middle of the room volume. The air gap between the two doors at the internal wall is also equipped with a sensor. Another sensor is placed at the HVAC air outlet to record switching between heating and cooling.

The external sensor below the $\mathrm{CR}$ floor is assumed to measure the external reference air temperature, because the TC from sunlight effectively shields it. An ISO Second Class Pyranometer (Kipp \& Zonen SMP3-V), which is mounted just above the aperture of the test specimen, records vertical irradiation on the south façade at intervals of $1 \mathrm{~min}$.

All temperature sensors comprise a probe head made of stainless steel with a diameter of $7 \mathrm{~mm}$ with an attached wire. The positions of the sensors are chosen to be not aligned orthogonally to the wall surface to avoid thermal bridging. In order to reduce thermal bridges by the cable, the last $300 \mathrm{~mm}$ are laid parallel to the wall.

\section{Calibration Measurement}

\subsection{Co-Heating Test to Characterize Thermal Response of the Cell}

The heat/cooling source of the TC is on an off-the-shelf HVAC unit to constrain the cost of the setup. Since such equipment does not provide the interfaces to instantaneously monitor electrical power utilization for heating and cooling, the thermal performance of the TC is characterized by a co-heating test (CHT). This approach is also called intrusive testing [22] and has been developed to determine characteristic building parameters using controlled heating tests.

The standard test allows a building's heat loss coefficient (HLC) to be quantified in situ by a quasi-stationary heating experiment. The HLC is calculated by the electric power consumption of heaters when the indoor air is heated to a constant temperature, e.g., $25^{\circ} \mathrm{C}$, over a longer time period [23]. It is assumed that the indoor air is homogeneously heated and distributed (employing fans) and that transient effects are of minor importance.

For the characterization of the TC, the test is adapted because of the high insulation and the small volume of the room. Instead of an only quasi-stationary procedure, the CHT is modified to dynamic and static heating modes. Therefore, a calibration measurement in four parts is carried out (see Figure 3):

1. cyclic heating with a high, defined power of the heat source,

2. interim heating by an HVAC unit

3. constant heating with a low, defined power consumption of the heat source, and

4. heating by an HVAC unit.

The adapted CHT aims at an accurate characterization of the TC's dynamic and static thermal response. For tests, the aperture in the south façade was closed with $400 \mathrm{~mm}$ thick panels of rock wool, causing the thermal properties of all walls to be equal. The external surface is protected by a plastic film.

During the modified CHT, the high and low power electrical consumption is known, whereas the HVAC power is unknown (details see the description in the following sections). As described above, in a quasi-stationary state, the total electrical power consumption of heaters is equal to the total heat losses, which contains all transmission and ventilation heat losses. In our case, the wall structures and thermal bridges are well known. Unfortunately, the air infiltration due to the joints within the south façade was not measured. Because the wooden plates are airtight and all joints sealed, only the south façade allows air infiltration and remains the only unknown heat loss. 


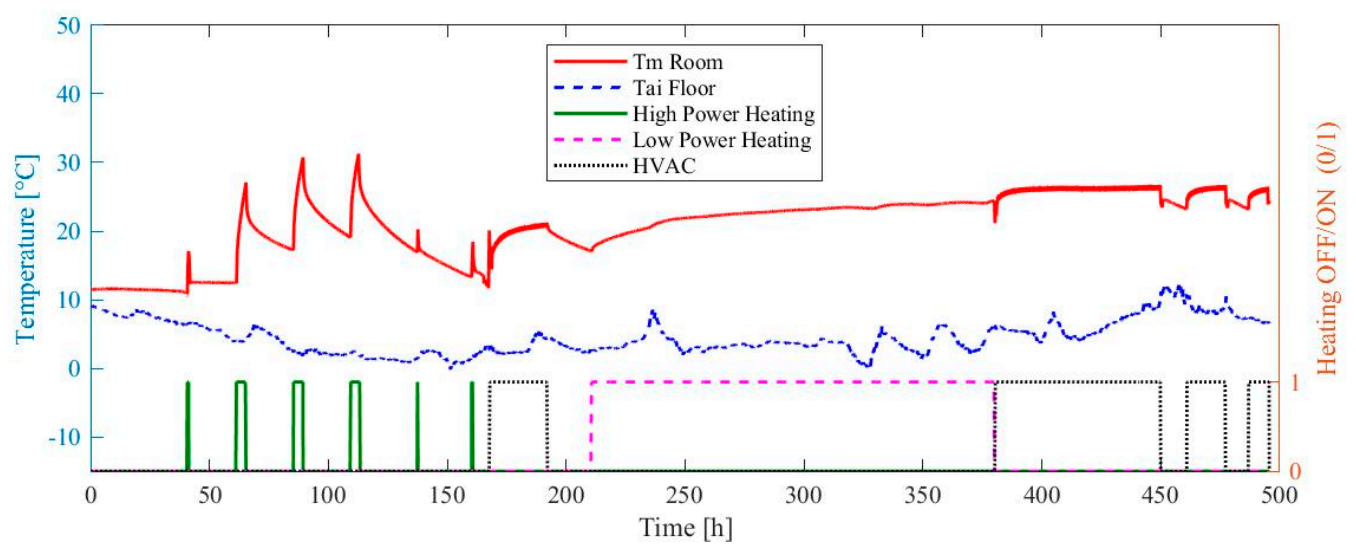

Figure 3. Development of external and conditioned room (CR) temperature (left axis) and activation of heating modes (right axis) during three week calibration measurement.

However, the infiltration air volume $V_{\text {inf }}$ could be calculated based on the $n_{50}$ air exchange rate determined by a blower door measurement according to EN 12831 [24] (withdrawn). The research presented in [25] indicates that the air infiltration based on [24] is over- or underestimating the real infiltration rate and, therefore, gives only a rough estimation. The low power heating test allows the infiltration heat losses to be determined.

The adapted CHT was performed from 14th November until 8th December 2019. This period was chosen for its steady weather conditions. According to hourly meteorological data taken from the MeteoSuisse database for Lucerne, the outdoor temperature varied between $0.1{ }^{\circ} \mathrm{C}$ and $12.8^{\circ} \mathrm{C}$ (average $5.1^{\circ} \mathrm{C}$ ), the wind speed from $0.2 \mathrm{~ms}^{-1}$ to $9.0 \mathrm{~ms}^{-1}$ (average $1.3 \mathrm{~ms}^{-1}$ ). With only 33 "sunny" hours, sky conditions were predominantly cloudy or overcast (over those three weeks only $3 \mathrm{~h}$ showed more than $30 \mathrm{~min}$ of direct solar radiation).

The accuracy of the CHT depends on the modelling method, which allows the experimental results to be related to the response of the TC to external conditions. Instead of linear regression to determine a stationary HLC, the data is compared to a transient Modelica simulation to increase the accuracy of this characterization.

\subsection{High Power Cyclic Heating}

Assuming $90 \mathrm{~m}^{2}$ surface area of the TC $(A)$, a target temperature difference $(\Delta \mathrm{T})$ of $25 \mathrm{~K}$ and a U-Value of $0.08 \mathrm{Wm}^{-2} \mathrm{~K}^{-1}$, the calculation of the heating power $\mathrm{P}_{h}$ to maintain the temperature, regardless of additional heat losses, can be estimated to:

$$
\mathrm{P}_{h}=A \cdot U \cdot \Delta \mathrm{T} \approx 180 \mathrm{~W}
$$

This power requirement is below the operational range of most commercial heaters starting at $500 \mathrm{~W}$. In fact, a constant heating power of $500 \mathrm{~W}$ could result in a room temperature of around $70{ }^{\circ} \mathrm{C}$ above the external air temperature, given the simulation of the TC. Therefore, the heating device was activated in an intermittent mode: its integrated timer set the heating device with rated $1250 \mathrm{~W}$ electrical power (measured as $1160 \mathrm{~W}$ by VOLTCRAFT EM 1000BASIC, accuracy $\pm(3 \%+2 \mathrm{~W})$ ) to one heating cycle of $4 \mathrm{~h}$ every $24 \mathrm{~h}$. Before the measurements, the TC with the aperture closed by the rock wool panels was prepared in free float mode so that all walls reached almost stationary equilibrium with its environment, as far the dynamic environment allowed.

The full measurement sequence consists of three heat periods of four hours per day where no additional fans were used. The heater was placed in the south-east quarter of the CR. Unforeseen maintenance work caused the additional three temperature peaks in Figure 3 and was documented. 


\subsection{Interim HVAC Heating}

To compensate the thermal disturbance of the cyclic heating test, the HVAC was used to heat the $\mathrm{CR}$ on a constant value $\left(20^{\circ} \mathrm{C}\right)$ over $24 \mathrm{~h}$, followed by a pause of natural cooling (ambient temperature was below $10^{\circ} \mathrm{C}$ ) of about $18.5 \mathrm{~h}$. The intention was to eliminate all remaining transient effects in the structure caused by the cyclic heating test before the low power heating test started.

\subsection{Low Power Heating}

The long-term heating test with reduced power is supposed to reach a quasi-stationary condition. The additional heat source consists of a cylindrical sheet-plate tube with three light bulbs rated $60 \mathrm{~W}$ therein and undisturbed ventilation, which is usually used to mimic the thermal load by an occupant. The device was also placed in the south-east quarter of the CR. The heat emitted by the incandescent lamps (wolfram wire) is assumed to be identical to their electric power consumption measured as $179 \mathrm{~W}$ (displayed value and total Wh/time by VOLTCRAFT EM 1000BASIC); no additional fan was used.

The test duration with constant light bulb heating was $169.5 \mathrm{~h}$. Prior transient simulations showed that this duration is needed to reach a quasi-stationary state. Moreover, the measured temperature data were observed on the ThingsBoard server during the test. The temperature change over time reached, as expected, a low value at the end of the low power heating period (less than $0.1 \mathrm{Kh}^{-1}$ or $47.7 \mathrm{~h}$ for the last $1 \mathrm{~K})$.

\subsection{HVAC Heating}

The HVAC unit, as described in Section 2.3, has four operating modes; heating, cooling, auto and dry. In heating mode, the unit maintains the room temperature (as measured by the internal sensor) above the set point, but is agnostic to overheating. The cooling mode displays inverse behavior, i.e., the cooling functionality is activated whenever the room temperature exceeds the set point temperature. In auto mode, the unit switches between cooling and heating. The details of the control algorithm are not available, but the measurements indicated a control dead band of about $\pm 2 \mathrm{~K}$.

The HVAC unit does not allow the measurement of the energy consumption or heating/cooling power, which depends on the external conditions. Consequently, the heating and cooling power had to be derived from measurements of the outlet temperature (by the sensor layout introduced in Section 2.4). Since inlet temperature is always equal to the room air temperature, heating or cooling power on a constant air flow rate can be calculated. Air flow rate can be fixed in cooling or heating mode, but not in auto mode.

During the measurement, the heating mode was tested with two set points of 20 and $26{ }^{\circ} \mathrm{C}$. The first set point was chosen to compensate the thermal disturbance between the high power cyclic heating and the low power heating tests. The heating mode was activated for $24 \mathrm{~h}$, followed by a pause of $183 / 4 \mathrm{~h}$.

The second set point was effective for $4 \frac{1}{2}$ days. For unknown reasons, the HVAC unit switched off twice for about 10.5 to $11.5 \mathrm{~h}$. These inactivity periods were recorded and considered in the simulations.

\section{Modeling the Test Cell in Modelica}

The Modelica simulation environment was used to model the dynamic behavior of the test cell. To reduce complexity of the detailed TC model, each of its subsystems such as walls, doors, thermal bridges, infiltration and equipment were divided into components. As an example, the wall subsystem comprises the five components external surface heat transfer, external plaster, insulation, wooden plate and internal surface heat transfer. All components consist of basic Modelica heat transfer or mass elements. The following subsections describe the implementation of the test cell model and the underlying assumptions and simplifications. 


\subsection{Wall Model}

All solid material layers are modeled as a combination of Modelica standard conductor and storage elements. Solid materials consist of 10 equidistant conductors and 11 mass elements. Nine of the latter represent $1 / 10$ th of the total thickness, while the remaining two stand for $1 / 20$ th of the total material thickness as surface elements. The heat flow per unit area for conductors $\Phi_{t c}$ and heat storage for masses $\Phi_{h s}$ are:

$$
\begin{gathered}
\Phi_{t c}=\Delta \mathrm{T} \cdot A \cdot \frac{\lambda}{d} \\
\Phi_{h s}=\operatorname{der}(\mathrm{T}) \cdot c \cdot \rho \cdot d \cdot A
\end{gathered}
$$

\subsection{Surface Heat Transfer}

Internal and external surface heat transfer have minor impact on heat loss regarding the high insulation level of the wall. Nevertheless, suitable models should be carefully selected. The following sections describe the applied model and the reasons behind it.

\subsubsection{External Surface Heat Transfer}

For forced external heat transfer, especially wind convection coefficient correlations, a wide variety of different models are available [26]. Complex wind convection models promise high accuracy in transient simulation but depend on reliable input data. However, wind speed and direction were not monitored during the experiments at the TC. Based on weather data for Lucerne, wind speed is typically below $2 \mathrm{~ms}^{-1}$.

The ISO 15099 [27] model for windward, which is constant for the typical wind speed range in Lucerne (during the experiment $<2 \mathrm{~m} / \mathrm{s}$ ), was chosen to calculate the forced convection $\mathrm{h}_{c v, e x}$ :

$$
\mathrm{h}_{c v, e x}=4.7+7.6 \cdot \mathrm{V}_{s} .
$$

With near-surface air speed $\mathrm{V}_{s}$ depending on wind speed $V$,

$$
\mathrm{V}_{s}=\left\{\begin{array}{c}
0.25 \cdot \mathrm{V} ; \mathrm{V}>2 \mathrm{~ms}^{-1} \\
0.5 ; \mathrm{V} \leq 2 \mathrm{~ms}^{-1}
\end{array}\right.
$$

External radiative heat transfer $\mathrm{h}_{r, e x}$ is mainly driven by the mean radiant temperature $\mathrm{T}_{r m}$. Therefore, its simplified radiation heat transfer calculation, based on a $\mathrm{T}^{4}$ correlation according to ISO 15099 [27], with external air temperature equal to mean radiant temperature is chosen.

$$
\mathrm{h}_{r, e x}=\varepsilon_{s} \cdot \sigma \cdot \frac{\left(\mathrm{T}_{s}{ }^{4}-\mathrm{T}_{r m}{ }^{4}\right)}{\mathrm{T}_{s}-\mathrm{T}_{r m}}
$$

The total heat flux for the external surface $\Phi_{t c, e x}$ is

$$
\Phi_{t c, e x}=\Delta \mathrm{T} \cdot\left(\mathrm{h}_{c v, e x}+\mathrm{h}_{r, e x}\right)
$$

\subsubsection{Internal Surface Heat Transfer}

The internal surface heat transfer coefficients (SHTC) and the convective heat transfer coefficients (CHTCs or $h_{c v}$ ) in particular show a high variance. Studies on TC of similar size compared to the version studied here report values of the CHTCs of 3 to $4 \mathrm{Wm}^{-2} \mathrm{~K}^{-1}$ for the walls [28]. However, other sources propose CHTCs between about 1.8 to $3.8 \mathrm{Wm}^{-2} \mathrm{~K}^{-1}$ for temperature difference of 2 to 
$25 \mathrm{~K}$ between wall and room air temperature [29]. The most common values assumed in building simulation are the $\mathrm{h}_{c v, \text { int }}$ of the EN ISO 6946 [21].

$$
\mathrm{h}_{c v, \text { int }}=\left\{\begin{array}{c}
5.0 \mathrm{~W} / \mathrm{m}^{2} \mathrm{~K} ; \text { upwards } \\
2.5 \mathrm{~W} / \mathrm{m}^{2} \mathrm{~K} ; \text { horizontal } \\
0.7 \mathrm{~W} / \mathrm{m}^{2} \mathrm{~K} ; \text { downwards }
\end{array}\right.
$$

Internal radiative surface heat transfer $\mathrm{h}_{r, \text { int }}$ is calculated in analogy with external transfer, based on an assumed $\mathrm{T}^{3}$-correlation for mean radiant temperature $\mathrm{T}_{r m}$ according to EN 6946 [21]:

$$
\mathrm{h}_{r, \text { int }}=\varepsilon \cdot 4 \sigma \cdot \mathrm{T}_{m}{ }^{3}
$$

The tabulated value for $\mathrm{h}_{\text {,int }}$ with emissivity $\varepsilon=0.9$ on $20^{\circ} \mathrm{C}$ is about 5.1 , resulting in a total internal SHTC of approximately $7.6 \mathrm{Wm}^{-2} \mathrm{~K}^{-1}$. Its reciprocal of $0.13 \mathrm{~m}^{2} \mathrm{KW}^{-1}$ evaluates to the standard $R_{s i}$ according to EN ISO 6946 [21]. Obviously, using a constant SHTC in a highly dynamic simulation is inappropriate. Therefore, a dynamic formulation for the total internal surface heat flux $\Phi_{t c . i n t}$, based on static $\mathrm{h}_{c v, \text { int }}$ and dynamic $\mathrm{h}_{r, \text { int }}$, with air temperature equal to the radiant temperature is applied.

$$
\Phi_{t c, i n t}=\Delta \mathrm{T} \cdot\left(\mathrm{h}_{c v, i n t}+\mathrm{h}_{r, \text { int }}\left(\mathrm{T}_{m}\right)\right)
$$

\subsection{Doors}

The door wings are modeled as solid materials (see Section 4.1) similar to the wooden plates. The enclosed air gap is modeled as a closed air cavity with convective $\Phi_{a i}$ and radiative heat conduction $\Phi_{r, g a p}$ according to ISO 15099 [27]:

$$
\Phi_{a i}=\Delta \mathrm{T} \cdot N u \cdot \frac{\lambda_{a i}}{d_{a i}}
$$

where $N u$ and $\lambda_{a i}$ are calculated with temperature dependent gas properties.

$$
\begin{gathered}
\Phi_{r, \text { gap }}=\Delta \mathrm{T} \cdot \mathrm{h}_{r} \\
\mathrm{~h}_{r}=\frac{4 \cdot \sigma \cdot \mathrm{T}_{m}{ }^{3}}{\frac{1}{\varepsilon_{1}}+\frac{1}{\varepsilon_{2}}-1}
\end{gathered}
$$

Note, $\mathrm{h}_{r}$ according to ISO 15099 [27] is more complex in order to respect the cavity dimensions. For the case of the double doors, it is assumed that the horizontal distance is much smaller than the height of the cavity, which reduces the formula to the same expression as in EN 6946 [21].

\subsection{Thermal Bridges}

Even high insulated buildings (and TCs accordingly) feature unavoidable thermal bridges. All geometric thermal bridges were analyzed in detail employing the thermal 2D finite element software Flixo. This includes the geometrical thermal bridges (edges) and inhomogeneity in structure (support beams in floor insulation). The sum of all thermal bridges of a room is considered as a static thermal conductor $\Phi_{\psi}$ from the rooms air node to the exterior, according to the following expression:

$$
\Phi_{\psi}=\Delta \mathrm{T} \cdot \sum\left(l_{i} \cdot \psi_{i}\right) .
$$

Values for thermal bridges $\sum\left(l_{i} \cdot \psi_{i}\right)$ are $0.96 \mathrm{WK}^{-1}$ for the conditioned and $0.55 \mathrm{WK}^{-1}$ for the MR. The thermal bridge coefficient of $0.92 \mathrm{WK}^{-1}$ for the $\mathrm{CR}$, compared to the external surface heat loss of $48 \mathrm{~m}^{2}$ and $0.082 \mathrm{Wm}^{-2} \mathrm{~K}^{-1}$ (results in $3.9 \mathrm{WK}^{-1}$ ), contributes significantly to the thermal system. Not at least, because internal dimensions were used to compute losses through the cell envelope, the contribution of thermal bridges to the total losses is rather high. 


\subsection{Infiltration}

Air infiltration and exfiltration are assumed to be exclusively forced and therefore be proportional to $\Delta \mathrm{T}$. Based on the method given by EN ISO 13790 (Formula (21)), heat loss by air in- and exfiltration is modeled as a thermal conductor $\Phi_{v e}$ between the CR air node and external air according to the following formula:

$$
\begin{gathered}
\Phi_{v e}=\mathrm{H}_{v e} \cdot \Delta \mathrm{T}=n \cdot 9.22 \frac{\mathrm{W}}{\mathrm{K}} \cdot \Delta \mathrm{T} \\
\text { with } \mathrm{H}_{v e}=q_{v} \cdot \rho_{a i} \cdot \mathcal{C}_{a i}=n \cdot \frac{1}{t} \cdot V_{r} \cdot \rho_{a i} \cdot c_{a i}=n \cdot 9.22 \mathrm{WK}^{-1}
\end{gathered}
$$

Air exchange rate $\mathrm{n}$ is kept variable as unitless coefficient for fine tuning of the energy balance. The other parameters can be fixed, such as $\rho_{a i}{ }^{*} c_{a i}=1200 \mathrm{~J} \mathrm{~m}^{-3} \mathrm{~K}^{-1}$ and the $\mathrm{CR}$ volume $V_{r}$ with $27.65 \mathrm{~m}^{3}$. Air change induced by wind is neglected. For the MR with an area of $19.26 \mathrm{~m}^{2}$ a coefficient of $6.42 \mathrm{WK}^{-1}$ is determined.

\subsection{Heating}

As mentioned in Section 3, three different heat sources, defined by the heating and cooling unit's mode of operation, were used in the experiment. All of them are controlled by a binary schedule that switches power on or off. Since no heat source achieves its full output instantaneously, the release of the heating/cooling power is subject to latency. This latency was measured for both the heater and the bulb heating devices to measure their respective heating and cooling ramps. This information allows us to describe the heaters' outputs as a trapezoid by their respective slopes at the beginning, during and after operation. Both devices take approximately $8 \mathrm{~min}$ to heat up and $20 \mathrm{~min}$ to cool down. The trapezoid control takes values of 0 to 1 ; the rising and falling segments are modeled linearly over the rising or falling time spans. This resulting curve is scaled by the heat flux to respect those transition zones.

The HVAC heating mode model is similar. Because of the unknown actual heating (or cooling) power, this value is set to an estimated value of $500 \mathrm{~W}$ with a rising time of $30 \mathrm{~s}$ and falling of $2 \mathrm{~min}$. This setting shows good agreement with the measured temperature changes in the CR.

For heating and cooling mode, the power is directly applied to the CR center node, which accounts for the thermal mass of the air volume. The model is simplified in that the air properties are fixed to $20^{\circ} \mathrm{C}$. The heater directly effects the air volume and is the source of radiative heat transfer to the CR surfaces.

To simplify the simulation, the effective radiating surface of the heater is considered to be $0.4 \mathrm{~m}^{2}$ with $\varepsilon=0.9$ and its temperature to be always $18 \mathrm{~K}$ above the measured air with heat flux applied to the $\mathrm{CR}$ center node. Due to the low power and small surface of the light bulb, it is not considered as a source of radiative heat exchange.

\section{Results}

Section 5 displays the results based on the test cell geometry and properties described in Section 2.2 and modelling approach described in Section 4 . The variable boundary conditions are the external air temperatures and heating devices, described in Section 3. For the Modelica simulations, the exterior air temperature sensor below the TC is used as standard external boundary condition. As described in Section 3, other than the other walls, the wall facing south was covered by a transparent plastic film. The low reflectance of the insulation caused higher solar absorption and created an external microclimate. Air temperatures just in front of the wall were measured in the range $-3^{\circ} \mathrm{C}$ up to $71^{\circ} \mathrm{C}$. These data were used as input for the simulation as exterior air and radiation temperature for the southern wall. Due to the low influence of external forced convection, the wind speed was held constant with $2 \mathrm{~m} / \mathrm{s}$. The in- and exfiltration rate was set to $\mathrm{n}=0.2$ (see Equation (16)) for the whole simulation. 
As described in Section 2.4 and Figure 2b, the temperature profiles of the walls, ceiling and floor are monitored by sensors in different layers. The simulation with Modelica allows for the temperature to be solved at any location in the walls and the measurements to compared in detail with the model predictions. Such comparisons are presented for the CR in the following subsections.

\subsection{Exterior Air Temperature}

As described in Section 4.2.1, the external heat transfer model does not respect the influence of the TC orientation and differing radiation conditions. Besides the external air sensor below the floor, the external air temperature is measured at the east wall, west wall and roof (ventilated air space). Those sensors are not placed to take accurate air temperature measurements, they are intended to get information about the microclimate effects. The differences between the external air temperatures using these sensors for one time-step ( $1 \mathrm{~min}$ ) vary in the range of $0.1 \mathrm{~K}$ to $7.5 \mathrm{~K}$ and on average, over the three weeks of the calibration period, by $1.2 \mathrm{~K}$ (see Figure 4). The differences are attributed to the exposure of all sensors, except for the one below the floor, to solar irradiation and the sky.

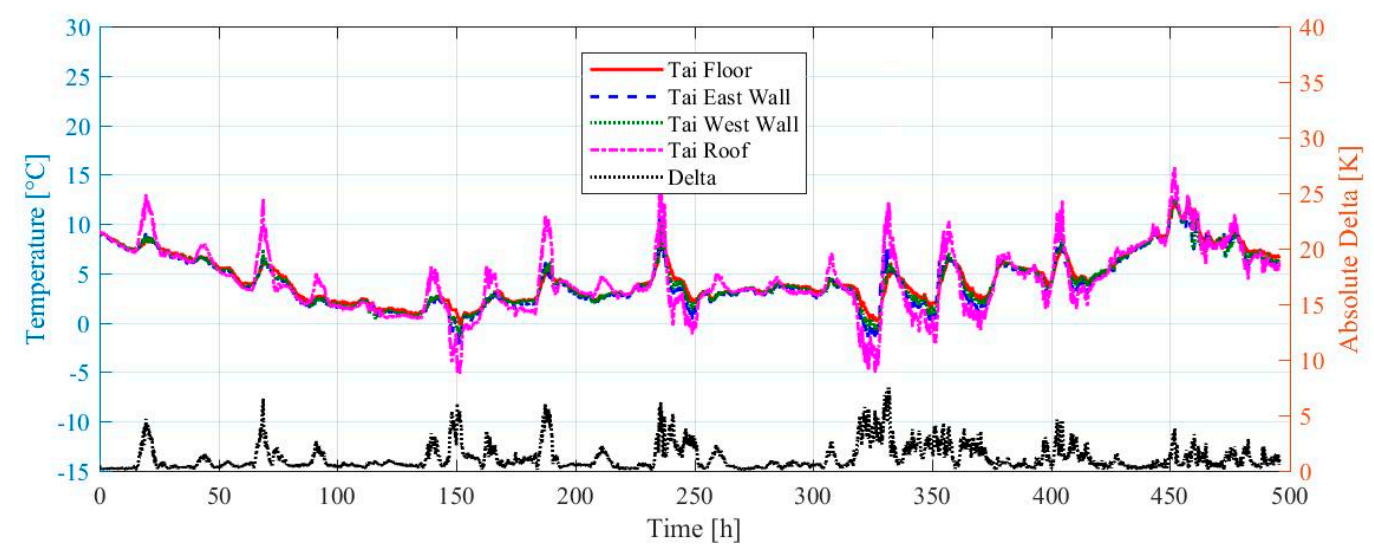

Figure 4. External air temperatures measured in front of surfaces of different orientations (left axis) with absolute delta of the four sensors (right axis).

\subsection{Interior Air Temperature}

As described above, both rooms contain a central air temperature sensor. The CR has additional air temperature sensors on each surface. Effects of stratification and the non-uniform temperature distribution in the air volume could be identified by the measurements:

- Air temperature below the ceiling is on average 1.2 $\mathrm{K}$ higher than above the floor (ranging from -2.1 to $10.6 \mathrm{~K})$.

- The maximum difference of air temperatures in front of the walls was found to be always below $5.7 \mathrm{~K}$, on average $0.5 \mathrm{~K}$.

- The temperature in the center of the air volume differed by -1.7 to $+6.7 \mathrm{~K}$ from the average temperature $T_{m}$ of all 7 air sensors, on average by $0.4 \mathrm{~K}$.

The higher (peak) variations were observed during the heating cycles. While the floor-ceiling difference is mainly caused by natural air convection, the differences on the walls may be influenced by the varying distance from heating devices (high and low power heating). The HVAC air exhaust does not blow directly on one of the sensors. It is common practice in building simulation to reduce room temperature to one node. Therefore, in the CR the average air temperature of all sensors $\mathrm{Tm}$ is used for the comparison between measurement and simulation. For the unconditioned MR, the centered air sensor is sufficient.

Figure 5 displays the results of the three weeks of calibration measurement and the corresponding simulation and deviation for the two room air temperatures. The average deviations between measurements and model are -0.2 and $-0.1 \mathrm{~K}$ for $\mathrm{CR}$ and MR respectively. 


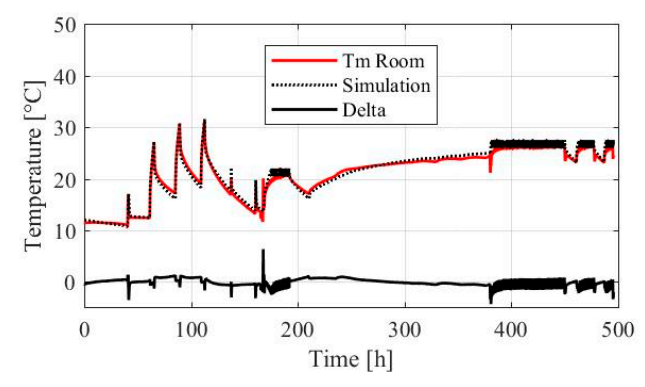

(a)

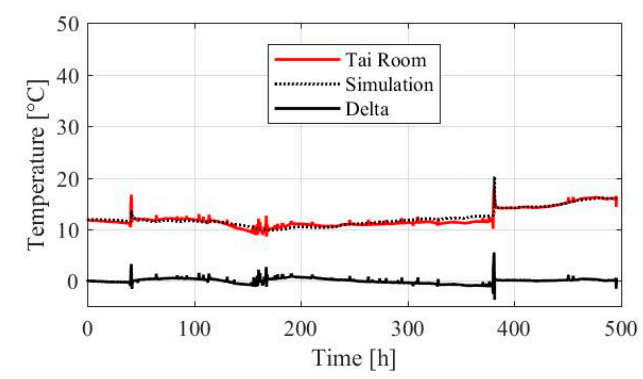

(b)

Figure 5. Room air temperatures measured, simulated and difference for (a) CR and (b) MR.

During the high power heating test (duration $72 \mathrm{~h}$ ), the highest differences were up to +1.1 and $-1.8 \mathrm{~K}$ (T measured-T simulated) for the CR and +1.4 and $-0.5 \mathrm{~K}$ for the unconditioned MR.

During the low power heating test (duration $169.5 \mathrm{~h}$ ), the highest difference was up to +0.9 and $-1.2 \mathrm{~K}$ (T measured-T simulated) for the CR and +2.9 and $-1.1 \mathrm{~K}$ for the MR.

During the second HVAC's "steady-state" heating period, the CR air node temperature varied from 25.9 to $27.8{ }^{\circ} \mathrm{C}$, while average Tm varied from 25.7 to $26.8{ }^{\circ} \mathrm{C}$. Similarly, the simulated air temperature varied from 26 to $27.5^{\circ} \mathrm{C}$. The detailed view shows that the cycles are similar but have slightly different periods.

\subsection{Layer Temperatures}

The comparison between simulation and measurement at intervals of one minute showed a high correlation with the Modelica simulation (see Figure 6). All peaks, valleys and slopes were reproduced accurately both in time and value. Table 4 shows a summary of the presented temperature differences on the five surfaces of the CR as well as the root mean square error (RMSE) [22]. The south wall was excluded because it was exposed to the most unsteady conditions. The average temperature difference in the five steady insulation cores was less than $\pm 0.4 \mathrm{~K}$. Only the core temperature of the southern insulation showed the highest differences between measurement and simulation of up to -1.4 and $+4.9 \mathrm{~K}$, on average $+1.1 \mathrm{~K}$.

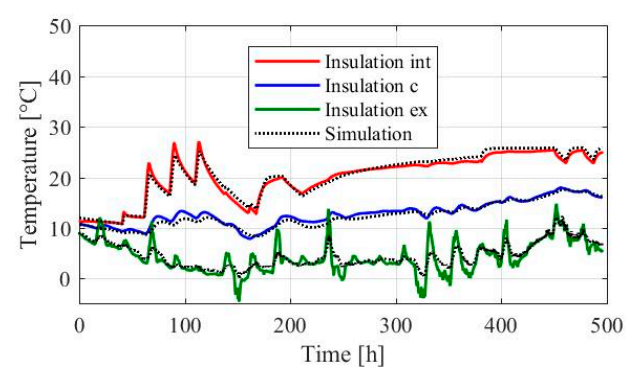

(a)

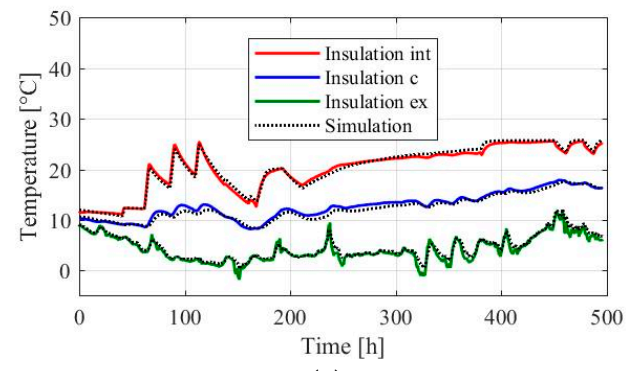

(c)

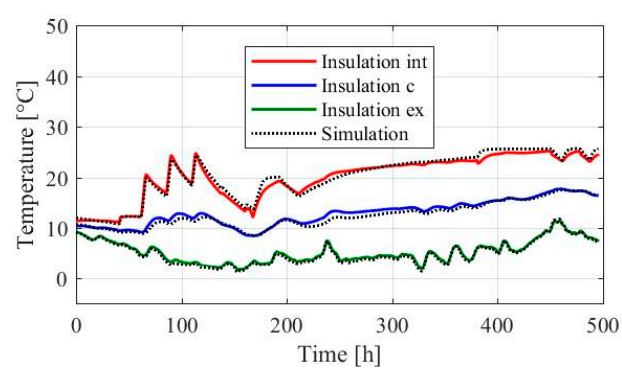

(b)

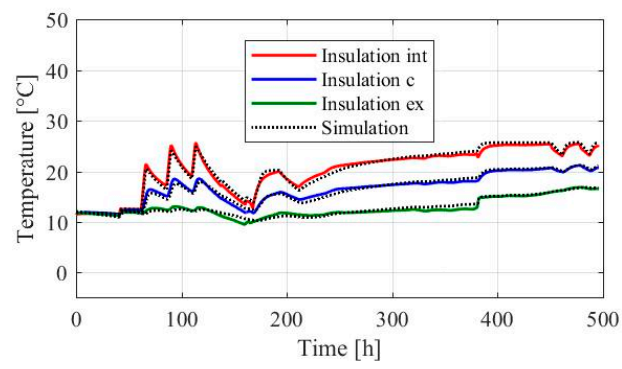

(d)

Figure 6. Measured and predicted layer temperatures for (a) ceiling, (b) floor, (c) exterior walls and (d) partition wall for internal insulation surface (Insulation int), insulation core (Insulation c) and external insulation surface (Insulation ex). 
Table 4. Summary of insulation layer differences.

\begin{tabular}{|c|c|c|c|c|c|c|}
\hline & \multicolumn{3}{|c|}{ Discrepancies } & \multicolumn{3}{|c|}{$\begin{array}{l}\text { Average } \\
R M S E\end{array}$} \\
\hline & Interior & Core & Exterior & Interior & Core & Exterior \\
\hline Conditioned Ceiling & -1.5 to +2.9 & -0.9 to +1.8 & -5.1 to +6.5 & $\begin{array}{c}-0.3 \\
0.7\end{array}$ & $\begin{array}{c}+0.4 \\
0.6\end{array}$ & $\begin{array}{c}-0.3 \\
1.5\end{array}$ \\
\hline Conditioned Floor & -2.1 to +1.4 & -0.3 to +1.5 & -0.5 to +0.8 & $\begin{array}{c}-0.3 \\
0.7\end{array}$ & $\begin{array}{c}+0.4 \\
0.6\end{array}$ & $\begin{array}{c}+0.3 \\
0.3\end{array}$ \\
\hline Conditioned Wall East/West & -1.6 to +1.2 & -0.7 to +1.5 & -2.8 to +1.6 & $\begin{array}{c}-0.1 \\
0.5\end{array}$ & $\begin{array}{c}+0.4 \\
0.6\end{array}$ & $\begin{array}{c}-0.4 \\
0.7\end{array}$ \\
\hline Partition Wall & -1.6 to +1.5 & -0.8 to +1.3 & -1.2 to +0.7 & $\begin{array}{c}-0.1 \\
0.6\end{array}$ & $\begin{array}{l}0.0 \\
0.4\end{array}$ & $\begin{array}{c}-0.1 \\
0.4\end{array}$ \\
\hline Air Cavity Inner Doors & & -1.7 to +2.6 & & & $\begin{array}{c}+0.4 \\
0.6\end{array}$ & \\
\hline North Wall (Maintenance) & -1.5 to +0.9 & -1.6 to +1.4 & -3.6 to +.5 & $\begin{array}{l}0.0 \\
0.4\end{array}$ & $\begin{array}{c}-0.2 \\
0.5\end{array}$ & $\begin{array}{c}-0.6 \\
1.0\end{array}$ \\
\hline South Wall & & -1.4 to +4.9 & & & $\begin{array}{c}+1.1 \\
1.3\end{array}$ & \\
\hline MR & & -3.8 to +5.6 & & & $\begin{array}{c}-0.1 \\
0.4\end{array}$ & \\
\hline $\mathrm{CR}$ & & -4.4 to +6.4 & & & $\begin{array}{c}-0.2 \\
0.7\end{array}$ & \\
\hline
\end{tabular}

Figure $6 \mathrm{c}$ shows measured and simulated temperatures only for the west wall, since no measurement data is available for the east wall due to a technical failure of the sensor. The simulation results for east and west wall are identical because the solar irradiation is neglected.

$$
R M S E=\sqrt{\frac{1}{n} \cdot \sum_{i=1}^{n}\left(\mathrm{~T}_{\text {measured }}-\mathrm{T}_{\text {simulated }}\right)^{2}}
$$

\section{Discussion}

\subsection{Measurement}

\subsubsection{Measurement Equipment}

As described in Section 2.4, the monitoring equipment is based on commercially available, low cost temperature sensors, which had been calibrated and offset-corrected. Nevertheless, the installation and sensor itself cause deviations/uncertainties in measurement results. The sensor head's thermal properties (diameter $7 \mathrm{~mm}$ stainless steel) themselves, and positional tolerance when installed in the insulation, lead to an additional measurement error $\Delta \mathrm{T}$. This error introduced by an assumed positional tolerance of $5 \mathrm{~mm}$ and a static temperature distribution in a $400 \mathrm{~mm}$ insulation, based on a temperature difference of $15 \mathrm{~K}$ (average in measurement period), is calculated as follows:

$$
\begin{gathered}
q=\Delta \mathrm{T} \cdot \frac{\lambda}{d}=15 \mathrm{~K} \cdot \frac{0.035 \frac{\mathrm{W}}{\mathrm{m} \cdot \mathrm{K}}}{0.4 \mathrm{~m}}=1.313 \mathrm{~W} / \mathrm{m}^{2} \\
\Delta \mathrm{T}_{(5 \mathrm{~mm})}=\frac{\mathrm{q}_{\text {flow }}}{\lambda} \cdot x=\frac{1.313 \frac{\mathrm{W}}{\mathrm{m}^{2}}}{0.035 \frac{\mathrm{W}}{\mathrm{m} \cdot \mathrm{K}}} \cdot 0.005 \mathrm{~m}=0.19 \mathrm{~K}
\end{gathered}
$$

Consequently, the sensor uncertainty due to mounting tolerances is assumed to be within a range of $\pm 0.2 \mathrm{~K}$. This range is lower than the observed discrepancies in Table 4 and, therefore, not crucial. 


\subsubsection{Measurement Quality}

The ceiling is expected to be the surface that is most affected by the simplifying assumptions on ambient air temperature (see Figure 6a). The reason for this effect is that the thermal behavior of the ventilated corrugated sheet roof can be expected to differ significantly from that of the other external surfaces. The exposure to the sky implies (a) a strong influence of solar irradiation over the entire day and (b) increased nighttime radiation exchange. This effect is also present in the simulations where the disagreement with the measurement for the temperature at the outer insulation surface is up to $+6.5 \mathrm{~K}$. The temperature discrepancies at the interior surface of the insulation are lower and reach only $+2.5 \mathrm{~K}$ during high power heating peaks. The temperature at the core of the insulation layer is influenced by the differences of both surfaces. However, the results in Table 4 show no significantly higher variability compared to the other surfaces.

The floor's composition differs slightly from that of the walls and the ceiling as it is covered by a wooden plate rather than plaster. As described in Section 4.1, the external air temperature is measured by the sensor placed below the floor. Due to the proximity of the sensors, the external insulation surface of the floor insulation displays the smallest deviations. The highest deviations were observed at the beginning of each HVAC cycle (see Figure $6 \mathrm{~b}$ ). This effect might be the result of air stratification, SHTC, and thermal mass of the floor plate, which is not represented by the simulation model.

Caused by the TC's geometry and construction, the wall facing west is less exposed to solar irradiance and its direct view to the sky is reduced due to partial occlusion by surrounding buildings. Nevertheless, the difference between the measured inner insulation surface temperatures of the two walls is smaller than $0.7 \mathrm{~K}$, less than $0.4 \mathrm{~K}$ for the insulation core, and smaller than $2 \mathrm{~K}$ for the external air near the surface for the observed period. Since the simulations do not account for solar irradiation and radiation to the sky, results for the east and west facing wall are identical. Due to the small deviation between the east and west measurements, the simplification to neglect solar irradiation and sky radiation exchange within the simulation is acceptable.

\subsection{Simulation}

\subsubsection{Additivity of the Modelica Model to Unexpected Events}

The flexible structure of Modelica based simulation was evident for successful simulation of the TC. It allowed testing and adapting different models and creating detailed, user defined control schedules. As shown in Figure 3, the high power heating unit was operated during three heating cycles of $4 \mathrm{~h}$ every $24 \mathrm{~h}$. This operation scheme causes the three temperature peaks $\left(>25^{\circ} \mathrm{C}\right) 2$ to 4. The small peaks $(1,5$ and 6$)$ are due to installation work and not part of the intended testing schedule. Nevertheless, it was possible to consider these additional peaks or heating powers in the Modelica simulation.

\subsubsection{External Temperature}

Relying on one single external air temperature is a simplification and leads to an expected error in the results. Nevertheless, inclusion of the air temperatures read from sensors on the walls and on top of the roof would also introduce errors due to solar irradiation, which are difficult to quantify without irradiance measurements for all orientations.

As described in Section 3, in contrast to the other walls, the wall facing south was covered by a transparent plastic film. The low reflectance of the insulation caused higher solar absorption and created an external microclimate that was reflected by the higher measured external temperatures that were accounted for in the model (see Section 5). The core temperature of the insulation showed differences between measurement and simulation of $-1.4 \mathrm{~K}$ and $+4.9 \mathrm{~K}$, on average $+1.1 \mathrm{~K}$. This deviation as well as the RSME of $1.3 \mathrm{~K}$ is significantly higher than in the other insulation cores with a RMSE $\leq 0.6$. 


\subsubsection{Surface Heat Transfer Coefficients}

While solid components are based on well-known physical characteristics and laws, the SHTCs are more complex and a suitable model has to be determined.

As described in Section 4.2.1, the ISO 15099 [27] windward model for forced external convection was chosen because the wind speed in Lucerne was below $2 \mathrm{~m} / \mathrm{s}$ most of the time (described in Section 3.1, only 35 hourly average wind speed values exceeded $2 \mathrm{~m} / \mathrm{s}$ ). The difference between the windward and leeward model of ISO 15099 [27] is, in this wind speed range, marginal (see Figure 7), while the standard model for forced convection from EN ISO 6946 [21] displays a high dependency to the actual wind speed. The method defined by ISO 15099 [27] is more complex; nevertheless, it is more robust regarding the lack of wind speed information.

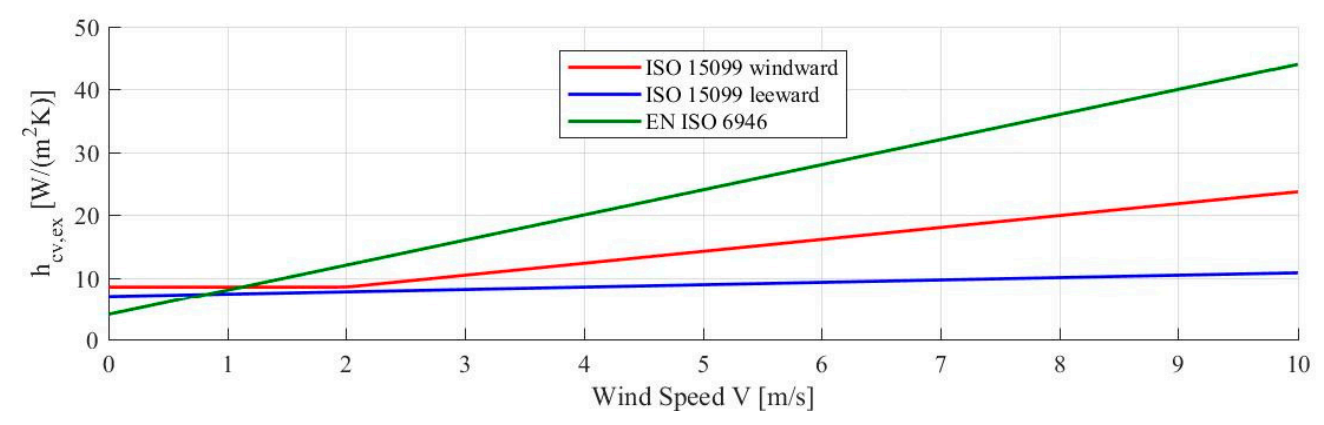

Figure 7. Comparison of $\mathrm{h}_{\mathcal{c v}, e x}$ formulas from ISO 15099 [27] and EN 6946 [21].

The radiative heat transfer to the sky influences the external SHTC, especially during cold nights with clear sky. The effect of nighttime cooling is visible in Figure 4, where the external air temperature of walls and ceiling show significantly lower temperatures at nighttime. A parameter study with the improved ISO 15099 [27] external radiation model showed a better prediction of the nighttime cooling effect. However, this radiation model needs information about the cloudiness degree, which was not measured, to quantify the nighttime radiation exchange to the sky. Otherwise, nighttime cooling is applied every night, which was also not the case during the measurement. A more detailed external SHTC model was therefore not applied.

The internal surface heat exchange is an important part of the whole simulation of our test cell. Hence, the effect of using static instead of dynamic SHTC according to EN ISO 6946 [21], and the full dynamic SHTC according ISO 15099 [27] (with dynamic natural convection), has been tested. This test led to results that differ by less than $1.5 \mathrm{~K}$ for the room air temperature. Higher deviations are obtained for the layer temperatures within the surfaces. The highest agreement between room air temperature and inner layer temperatures was reached with the semi-dynamic EN 6946 [21] correlation as described in Section 4.2.2.

During HVAC modes, the integrated fan causes turbulence and mixing of $\mathrm{CR}$ air. According to the HVAC specifications in Table 2, the minimum air volume flow is approximately $9 \mathrm{~h}^{-1}$. This implies that the forced air movement affects (enlarges) the internal SHTC. As is visible in Figure 6, the internal insulation layer is close to the simulated temperature. During HVAC modes, in hour 168 to 192 and 380 to 496 , the inner insulation surface of the prediction reacts faster than the measurement to the changed conditions. This means that the simulation overestimates the heat flow rather than underestimates it due to the air movement.

\subsubsection{High Power Heating}

The three peaks caused by the heating cycles were the most challenging part of the simulation, since replicating them requires the accurate modeling of the entire TC's transient response. Preliminary simulations predicted a slightly lower air temperature and a significantly lower layer temperature compared to the experimental results. The deviation could be attributed to the heat storage capacity of 
the wooden plates (see Table 1), which form the only effective thermal mass in the TC. Initially, the average density and heat storage capacity according to the manufacturer's datasheet were used. It turned out that those values have to be set on the lower end of the range indicated by the manufacturer to minimize the disagreement between simulation and measurement. A reason for this underestimation of the capacity values may be that the wooden plates of "industrial" quality have more cavities, implying lower density and heat capacity.

At this point is has to be mentioned that the conductivity of the wooden plates could also be affected by the lower quality. The adjusted properties are $-2.3 \%$ for the average for the density and $-9.6 \%$ for the heat storage capacity, related to the average tabulated value by the manufacturer 8 see Table 1. This resulted in a significant influence on the simulation. A variation of conductivity of $\pm 10 \%$ showed no differences for room air temperature or position $b$ sensors according Figure $2 b$.

\subsubsection{Low Power Heating and Air Infiltration}

As the air permeability was not measured, the influence of air infiltration was determined by the simulation. Therefore, the infiltration rate $n$ was varied until the best match to the measurements was observed. The simulated temperature in the CR at the end of the low power heating period was initially, without the infiltration model, significantly higher than the measurement. Setting air in- and exfiltration (assumed to be proportional to the temperature difference) in Equation (15) to $n=0.2$ displayed the best correlation between cooling over the whole calibration period and the reduction of $\mathrm{CR}$ air temperature during the low power heating test.

Based on Equation (20) according to [24], the corresponding blower door value $n_{50}$ can be calculated. The air exchange rate in $n$ in Equation (15) is equal to $\mathrm{V}_{\text {inf }} / \mathrm{V}_{i}$. In addition, the shielding coefficient $e_{i}(=0.03)$ and the height correction factor $\varepsilon(=1.0)$ are needed. For this setting, the $\mathrm{n}_{50}$ is about $3.3 \mathrm{~h}^{-1}$, which means a good sealing quality of a building. Better results could only be achieved by a trace-gas test.

$$
\mathrm{V}_{\text {inf }}=2 \cdot \mathrm{V}_{i} \cdot \mathrm{n}_{50} \cdot e_{i} \cdot \varepsilon
$$

\subsection{Simulation Error}

Most available literature about test cell measurement, simulation and validation is based on hourly intervals [30]. Nevertheless, data was collected every minute and the Modelica simulation also supports that interval.

The accuracy target of temperature prediction is $\pm 1 \mathrm{~K}$. Table 5 shows the percentage in which this accuracy target is reached, at least $90 \%$ for the $\mathrm{CR}$ air temperatures and $64.6 \%$ for insulation measuring points (regardless external insulation surface of the ceiling, the minimum is $80 \%$ ). It is vital for the interpretation of these results that the measurement values are recorded every minute. Together with the observed interruptions (installation work) during the measurement period, the simulation is of high accuracy. With an accuracy of $\pm 1.5 \mathrm{~K}$, over $96 \%$ of the minute values of air volumes and internal layer temperatures are within this error band.

\subsection{Test Cell}

The TC was designed to provide a conditioned room that allows the response of test façades to changing environmental conditions to be investigated. The proposed TC setup is inspired by the PASSYS/PASSLINK TCs but reduces the heterogeneity of the sensor network by avoiding direct measurement of heat flux. Instead, the temperature profiles in the building elements are monitored and this parametrizes the computation of heat flux using a validated model that mimics the static and dynamic response of the TC. The results show the validity of this model. Errors could be attributed to the lack of infiltration measurement, uncertain properties of the wooden plate material, and the chosen model for interior SHTC. The main assumptions that led the development of the model are confirmed by the results. 
Table 5. Percentile of simulated time steps within precision requirements.

\begin{tabular}{ccccccc}
\hline & \multicolumn{3}{c}{ within $\pm \mathbf{1 . 0 0}$ K } & \multicolumn{3}{c}{ within $\pm \mathbf{1 . 5 0}$ K } \\
\hline & Internal & Core & External & Internal & Core & External \\
\hline Conditioned Ceiling & $87.1 \%$ & $89.0 \%$ & $64.6 \%$ & $97.5 \%$ & $98.1 \%$ & $75.1 \%$ \\
Conditioned Floor & $83.9 \%$ & $87.9 \%$ & $100.0 \%$ & $96.2 \%$ & $100.0 \%$ & $100.0 \%$ \\
Conditioned Wall West & $98.1 \%$ & $93.6 \%$ & $85.1 \%$ & $99.8 \%$ & $100.0 \%$ & $93.9 \%$ \\
Partition Wall & $96.0 \%$ & $98.6 \%$ & $89.2 \%$ & $99.6 \%$ & $100.0 \%$ & $100.0 \%$ \\
Air Cavity Inner Doors & & $89.2 \%$ & & & $98.8 \%$ & \\
North Wall (Maintenance) & $99.8 \%$ & $89.3 \%$ & $80.3 \%$ & $100 \%$ & $99.8 \%$ & $86.2 \%$ \\
South Wall & & $48.0 \%$ & & & $69.7 \%$ & \\
MR Air & & $96.3 \%$ & & & $99.7 \%$ & \\
CR Air & & $90.3 \%$ & & & $95.9 \%$ & \\
\hline
\end{tabular}

The presented validation deliberately excludes response to radiative heat transfer that would occur in the intended characterization of transmissive façade elements but aims at the isolated validation of heat transfer through the invariant, opaque building elements of the TC. For the intended testing of transmissive façade elements, a second validation will be performed addressing the solar gains model of the TC.

\section{Conclusions and Future Work}

The presented work describes various experimental approaches to design and characterize a test cell as well as a numerical model for its simulation. Valuable insight of transient characteristics and simulation parameters were gained and presented. Regarding the cost-effective design, the TC calibration measurement and simulation were a full success. The Modelica simulation as well as the monitoring strategy is considered to be reliable and a solid base for future work and development.

Regarding the experimental approach, the targeted accuracy of $\pm 1 \mathrm{~K}$ is rather ambitious. This is also aggravated by the high time resolution of the experimental campaign. Whereas most building simulations are based on hourly data, the measurement with minute time resolution reports every single interruption or discrepancy and leads to a high amount of data, but for future work, the high resolution and the resulting in-depth understanding is essential.

Valuable information about the short-term transient behavior was gained during the cyclic high power heating test. While standard CHTs (see Section 3.1) reduce all not directly relatable heat losses to the HLC, the nature of this calibration measurement allowed a more detailed characterization. Due to the steady-state condition of the CHT, it cannot account for heat storage effects. The simulation due to the transient model could closely replicate even peaks in the high power cycles. The low power heating test allowed the characterization of the heat fluxes under almost static conditions and determined the lacking air infiltration rate. In addition, even the unexpected maintenance work, with its thermal interruptions, confirmed the simulation model.

The success of simulation always depends on the accuracy of exterior and interior boundary conditions, whereby the performance of highly insulated façades is less environment dependent than poorly insulated façades. The results for the ceiling and east/west walls confirm the minor role of solar irradiance or clear sky radiation for the external surfaces in this experiment. On the other hand, the control strategy and modelling of internal sources is highly relevant. Even simple tests require accurate modelling to achieve reliable simulation results.

In the next step, the prototype of a novel façade element, the Solar Energy Balanced Façade (SEBF), will be mounted and characterized at the south façade. The façade module with its double skin façade (DSF) structure with thermal mass within the DSF has been modeled in Modelica and preliminary simulations have been completed. The next challenge is to combine the SEBF with the test cell simulation and compare it to the measurements. Because of the thinner structure and solar dependent thermal behavior, the simulation approach is again on trial. 
Supplementary Materials: The following are available online at http://www.mdpi.com/2075-5309/9/10/209/s1, Excel with data basis for Figures 3-7 and Table 4.

Author Contributions: Conceptualization, T.W.; Data curation, T.W.; Funding acquisition, A.L.; Investigation, T.W.; Methodology, P.S.; Project administration, A.L.; Resources, A.L.; Software, T.W. and P.S.; Validation, P.S.; Visualization, T.W.; Writing-original draft, T.W.; Writing—review \& editing, P.S. and A.L.

Funding: This research was funded by the Swiss National Science Foundation, grant number IZCNZ0-174562.

Acknowledgments: Our deep gratitude goes to the companies FLUMROC Switzerland and Sto for their material sponsoring and support.

Conflicts of Interest: The authors declare no conflicts of interest.

\section{References}

1. Attia, S.; Bilir, S.; Safy, T.; Struck, C.; Loonen, R.; Goia, F. Current trends and future challenges in the performance assessment of adaptive façade systems. Energy Build. 2018, 179, 165-182. [CrossRef]

2. Clarke, J.A.; Hensen, J. Integrated building performance simulation: progress, prospects and requirements. Build. Environ. 2015, 91, 294-306. [CrossRef]

3. Burhenne, S.; Wystrcil, D.; Elci, M.; Narmsara, S.; Jerkel, S. Building performance simulation using Modleica: Analysis of the current state and application areas. In Proceedings of the BS2013 13th Conference of BPSA, Chambéry, France, 26-28 August 2013; p. 32593266.

4. Wetter, M. Modelica-based Modelling and Simulation to Support Research and Development in Building Energy and Control Systems. J. Build. Perform. 2009, 2, 143-161. [CrossRef]

5. Wetter, M. A View on Future Building System Modeling and Simulation. In Building Performance Simulation for Design and Operation; Routledge: London, UK, 2011.

6. Müller, D.; Lauster, M.; Constantini, A.; Fuchs, M.; Remmen, P. AIXLIB-An Open-Source Modelica Library within the IEA-EBC Annex 60 Framework. BauSIM 2016, 2016, 3-9.

7. Wetter, M.; Zuo, W.; Nouidui, T.S.; Pang, X. Modelica Buildings library. J. Build. Perform. Simul. 2014, 7, 253-270. [CrossRef]

8. Wetter, M.; Bonvini, M.; Nouidui, T.S.; Tian, W.; Zuo, W. Modelica Buildings Library 2.0. In Proceedings of the BS2015 14th Conference of International Building Performance Simulation Association, Hyderabad, India, 7-9 December 2015.

9. Baker, P.; van Dijk, H. PASLINK and dynamic outdoor testing of building components. Build. Environ. 2008, 43, 143-151. [CrossRef]

10. Gicquel, R. The Project PASSYS. In Solar Energy Applications to Buildings and Solar Radiation Data; Springer: Brussels, Belgium, 1988; pp. 167-178.

11. Strachan, P.; Vandaele, L. Case studies of outdoor testing and analysis of building components. Build. Environ. 2008, 43, 129-142. [CrossRef]

12. Olivieri, L.; Caamano, E.; Olivieri, F.; Neila, J. Integral energy performance characterization of semi-transparent photovoltaic elements for building integration under real operation conditions. Energy Build. 2014, 68, $280-291$. [CrossRef]

13. Leon-Rodriguez, A.L.; Suarez, R.; Bustamante, P.; Campano, M.A.; Moreno-Rangel, D. Design and Performance of Test Cells as an Energy Evaluation Model of Facades in a Mediterranean Building Area. Energies 2017, 10, 1816. [CrossRef]

14. Bianco, L.; Schneuwly, P.; Brun, A. Design of a new full-scale facility for building envelope test: FACT (FACade Tool). Energy Procedia 2017, 111, 256-266. [CrossRef]

15. Jensen, S.Ø. Experimental data set for validation of heat, air and moisture transport models of building envelopes. Build. Environ. 2011, 46, 1038-1046.

16. Erkoreka, A.; Bloem, J.J.; Escudero, C.; Martin, K.; Sala, J.M. Optimizing full scale dynamic testing of building components: measurement sensors and monitoring systems. Energy Procedia 2015, 78, 1738-1743. [CrossRef]

17. Wüest, T.; Luible, A. Trombe Curtain Wall Façade. J. Facade Des. Eng. 2019. [CrossRef]

18. Wüest, T.; Luible, A. Solar Energy Balanced Façade. Façade 2018-Adaptive! In Proceedings of the COST Action TU1403 Adaptive Facades Network Final Conference, KKL Lucerne, Switzerland, 26-27 November 2018; pp. 183-194. 
19. Facade Test Rig. Available online: https://www.hslu.ch/de-ch/technik-architektur/forschung/ kompetenzzentren/gebaeudehuelle/fassaden-und-metallbau/infrastruktur/fassadenpruefstand (accessed on 24 September 2019).

20. Wouters, P.; Vandaele, L. The PASSYS Test Cells-A Common Outdoor Test Facility for Thermal and Solar Building Research; Commission: Brussels, Belgium, 1990.

21. EN ISO 6946:2017. Building Components and Building Elements-Thermal Resistance and Thermal Transmittance-Calculation Methods; European Committee for Standardization: Brussels, Belgium, 2017.

22. Coakley, D.; Raftery, P.; Keane, M. A review of methods to match building energy simulation models to measured data. Renew. Sustain. Energy Rev. 2014, 37, 123-141. [CrossRef]

23. Bauwens, G.; Roels, S. Co-heating test: A state-of-the-art. Energy Build. 2014, 82, 163-172. [CrossRef]

24. EN 12831:2003. Heating Systems in Buildings-Method for Calculation of the Design Heat Load, Withdrawn! European Committee for Standardization: Brussels, Belgium, 2003.

25. Charisi, S.; Waszczuk, M.; Thiis, T.K. Determining building-specific wind pressure coefficients to account for the microclimate in the calculation of air infiltration in buildings. Adv. Build. Energy Res. 2019, 1-22. [CrossRef]

26. Palyvos, J. A survey of wind convection coefficient correlations for building envelope energy systems' modeling. Appl. Therm. Eng. 2008, 28, 801-808. [CrossRef]

27. ISO 15099:2003. Thermal Performance of Windows, Doors and Shading Devices_Detailed Calculations; International Standards Organization: Geneva, Switzerland, 2003.

28. Awbi, H.; Hatton, A. Natural convection from heated room surfaces. Energy Build. 1999, 30, $233-244$. [CrossRef]

29. Fohanno, S.; Polidori, G. Modelling of natural convective heat transfer at an internal surface. Energy Build. 2006, 38, 548-553. [CrossRef]

30. Manz, H.; Loutzenhiser, P.; Frank, T.; Strachan, P.; Bundi, R.; Maxwell, G. Series of experiments for empirical validation of solar gain modeling in building energy simulation codes-Experimental setup, test cell characterization, specifications and uncertainty analysis. Build. Environ. 2006, 41, 1784-1797. [CrossRef]

(C) 2019 by the authors. Licensee MDPI, Basel, Switzerland. This article is an open access article distributed under the terms and conditions of the Creative Commons Attribution (CC BY) license (http://creativecommons.org/licenses/by/4.0/). 